Research Paper

\title{
Stanniocalcin-1 Controls Ion Regulation Functions of Ion-transporting Epithelium Other than Calcium Balance
}

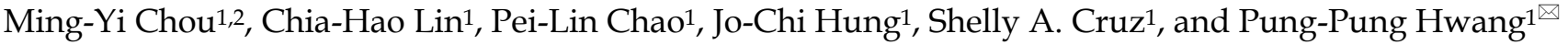 \\ 1. Institute of Cellular and Organismic Biology, Academia Sinica, Taipei 11529, Taiwan. \\ 2. RIKEN Brain Science Institute, Laboratory for Developmental Gene Regulation, 2-1 Hirosawa, Wako, Saitama, 351-0198, Japan.
}

$\triangle$ Corresponding author: P. P. Hwang, Institute of Cellular and Organismic Biology, Academia Sinica, Taipei 11529, Taiwan. E-mail: pphwang@gate.sinica.edu.tw; TEL: +886-2-27899521; FAX: +886-2-27899576.

(c) Ivyspring International Publisher. This is an open-access article distributed under the terms of the Creative Commons License (http://creativecommons.org/ licenses/by-nc-nd/3.0/). Reproduction is permitted for personal, noncommercial use, provided that the article is in whole, unmodified, and properly cited.

Received: 2014.10.10; Accepted: 2014.11.18; Published: 2015.01.01

\begin{abstract}
Stanniocalcin-1 (STC-1) was first identified to involve in $\mathrm{Ca}^{2+}$ homeostasis in teleosts, and was thought to act as a hypocalcemic hormone in vertebrate. Recent studies suggested that STC-1 exhibits broad effects on ion balance, not confines to $\mathrm{Ca}^{2+}$, but the mechanism of this regulation process remains largely unknown. Here, we used zebrafish embryos as an alternative in vivo model to investigate how STC-1 regulates transepithelial ion transport function in ion-transporting epithelium. Expression of stc-l mRNA in zebrafish embryos was increased in high-Ca ${ }^{2+}$ environments but decreased by acidic and ion-deficient treatments while overexpression of stc-l impaired the hypotonic acclimation by decreasing whole body $\mathrm{Ca}^{2+}, \mathrm{Na}^{+}$, and $\mathrm{Cl}^{-}$contents and $\mathrm{H}^{+}$secretion ability. Injection of STC-1 mRNA also down-regulated mRNA expressions of epithelial $\mathrm{Ca}^{2+}$ channel, $\mathrm{H}^{+}$-ATPase, and $\mathrm{Na}^{+}-\mathrm{Cl}^{-}$cotransporter, suggesting the roles of STC-1 in regulation of ions other than $\mathrm{Ca}^{2+}$. Knockdown of STC-1 caused an increase in ionocyte progenitors (foxi3a as the marker) and mature ionocytes (ion transporters as the markers), but did not affect epithelium stem cells (p63 as the marker) in the embryonic skin. Overexpression of STC-1 had the corresponding opposite effect on ionocyte progenitors, mature ionocytes in the embryonic skin. Taken together, STC-1 negatively regulates the number of ionocytes to reduce ionocyte functions. This process is important for body fluid ionic homeostasis, which is achieved by the regulation of ion transport functions in ionocytes. The present findings provide new insights into the broader functions of STC-1, a hypocalcemic hormone.
\end{abstract}

Key words: stanniocalcin, ion regulation, differentiation, ionocyte, zebrafish.

\section{Introduction}

Stanniocalcin-1 (STC-1), a homodimeric glycoprotein, was originally identified in bony fish and later in other vertebrates [1]. STC-1 acts as a hypocalcemic hormone, which down-regulates the concentration of serum $\mathrm{Ca}^{2+}$ [2]. By negatively regulating epithelial calcium channel $(\mathrm{ECaC})$ gene expression, STC-1 reduces $\mathrm{Ca}^{2+}$ uptake in fish embryos [3]. STC-1 is also involved in maintaining the balance of $\mathrm{Na}^{+}$and $\mathrm{Cl}^{-}$. In rainbow trout, a decrease in the plasma $\mathrm{Na}^{+}, \mathrm{Cl}^{-}$ and $\mathrm{Na}^{+}$and $\mathrm{Ca}^{2+}$ concentrations caused an increase in the plasma STC-1 level, implying a broader role than the classical hypocalcemic function of STC [4]. The STC-1 concentration in seawater-adapted flounder corpuscles of Stannius was reported to be 3-fold higher than that in freshwater-adapted ones, suggesting that environmental salinity stimulates STC-1 synthesis [5]. In mammals, it was reported that STC-1 suppressed intestinal $\mathrm{Ca}^{2+}$ absorption and renal phosphate excretion, and stimulated intestinal phosphate uptake [6, 7]. STC-1 gene expression was induced by water deprivation, indicating the role of STC-1 in control of natriuresis and kaliuresis [8]. 
However, STC-1(-/-) null mice showed normal serum $\mathrm{Ca}^{2+}$ and phosphate levels [9], which conflicts with the functions of STC-1 on in mineral homeostasis in mammals. Additional evidences are necessary to elucidate the roles of STC-1 in body fluid ionic homeostasis in vertebrates.

Mammalian STC was identified during the last decade, and this discovery led to the important conclusions that STC is not unique to fish, and it has multiple functions [2]. STC-1 participates in several physiological processes, including anti-inflammatory mechanisms [10], antioxidant mechanisms [11, 12], growth plate chondrogenesis [13], adipogenesis, and tumorigenesis [14]. Recent studies showed that STC-1 is up-regulated in several cancers [15-17], and it is thought to be a molecular marker for human cancer [18]; these findings imply that STC-1 acts as a modulator for cell proliferation or differentiation. By up-regulating vascular endothelial growth factor expression, STC-1 enhances tumor angiogenesis in gastric cancer [19]. In mammalian fat tissue, STC-1 is highly expressed in terminally differentiated adipocytes that maintain the integrity of mature adipose tissue [20]. STC-1 is also involved in re-epithelialization during wound healing, through the induction of cell migration [21]. These findings suggest that STC-1-mediated modulation of proliferation and/or differentiation of several cell types fulfill various physiological demands. The significant results from the studies investigating the role of STC-1 on cell proliferation and differentiation regulation, however, mainly provided in vitro data by using cultured cells or cell lines. In contrast, the STC-1(-/-) null mice showed normal fertility, fecundity, development, and weight gain $[9,22]$, which do not support the findings in cultured cells; making it become an uncertain issue for the regulatory roles of STC-1 in cell proliferation and differentiation.

To better explore this issue, we used zebrafish as an alternative in vivo model; this organism is well-suited to both genetic manipulation and molecular/cellular physiological methodologies, and we have previously used it to investigate the roles of hormone control in physiological responses [23-29]. We have also established the methodology and strategy to understand the mechanisms of ionocyte differentiation in zebrafish [29-32]. To date, four type of zebrafish ionocyte were identified to be responsible for transporting various ions by different ion transporters in the embryonic stages [33-39]. During development, ionocyte progenitors appear in the embryonic skin and become mature and functional ionocytes at around 24 hour post-fertilization (hpf) while the gills are not fully functional $[29,31]$. Hence, the zebrafish offer an excellent system for us to study the functions of STC- 1 and these results obtained are not only important for fish physiology but also bring some clues to mammalian studies.

In the present study, we aimed to test the hypothesis that STC-1 is involved in the regulation of ions (other than $\mathrm{Ca}^{2+}$ ) by elucidating the mechanism that how STC-1 regulates transepithelial ion transport function for body fluid homeostasis. We reported here that STC-1 mRNA expression was decreased not only by different $\mathrm{Ca}^{2+}$ treatments, but also by acidic and ion-deficient environments. Manipulating the expression of STC-1 protein through injection of morpholino oligonucleotides and mRNA respectively increased and decreased the numbers of skin ionocytes and ionocytes progenitors. Our results suggest that STC-1 is a negative modulator of ionocyte differentiation and thus controls ion regulatory function for body fluid ionic homeostasis.

\section{Materials and Methods}

Experimental animals. Zebrafish (Danio rerio) were kept in local tap water at $28.5^{\circ} \mathrm{C}$ under a $14: 10-\mathrm{h}$ light-dark photoperiod at the Institute of Cellular and Organismic Biology, Academia Sinica, Taipei, Taiwan. Experiments were performed in accordance with the guidelines of the Academia Sinica Institutional Animal Care and Utilization Committee (approval no. RFiZOOHP2007086).

Acclimation experiments. High- $(2 \mathrm{mM})$ or low-Ca ${ }^{2+}(0.02 \mathrm{mM})$ artificial freshwater was prepared by supplementing double-deionized water (model Milli-RO60; Millipore, Billerica, MA, USA) with the appropriate levels of $\mathrm{CaSO}_{4} \cdot 2 \mathrm{H}_{2} \mathrm{O}, \mathrm{MgSO}_{4} \cdot 7 \mathrm{H}_{2} \mathrm{O}$, $\mathrm{NaCl}, \mathrm{K}_{2} \mathrm{HPO}_{4}$, and $\mathrm{KH}_{2} \mathrm{PO}_{4}$. With the exception of $\mathrm{Ca}^{2+}$, the concentrations of the other ions in all solutions were the same as those in local tap water (control freshwater; [Ca ${ }^{2+}$ ], $0.2 \mathrm{mM}$; $\left[\mathrm{Na}^{+}\right], 0.5 \mathrm{mM}$; $\left[\mathrm{Mg}^{2+}\right.$, $0.16 \mathrm{mM}$; and $\left[\mathrm{K}^{+}\right], 0.3 \mathrm{mM}$; $\mathrm{pH}$ 7.1 7.4). Ion concentrations were maintained within $10 \%$ of the predicted values. The acidic medium ( $\mathrm{pH} 4.00 \sim 4.05)$ was made by adding $\mathrm{H}_{2} \mathrm{SO}_{4}$ to control freshwater; the concentrations of other ions in acidic freshwater were the same as those in control freshwater. Zebrafish embryos right after fertilization were incubated in different artificial media (high- $\mathrm{Ca}^{2+}, \mathrm{low}-\mathrm{Ca}^{2+}$, or acidic) and control freshwater for $4 \mathrm{~d}$. Zebrafish embryos at 3 d-post fertilization were treated with double-deionized water for $1 \mathrm{~d}$. During the experiments, ion concentrations were maintained within $10 \%$ of the predicted values.

RNA extraction. Twenty-five zebrafish embryos were pooled as a sample and homogenized in $0.5 \mathrm{~mL}$ Trizol reagent (Invitrogen, Carlsbad, CA), before being mixed with $0.1 \mathrm{~mL}$ chloroform and thoroughly shaken. After centrifugation at $4{ }^{\circ} \mathrm{C}$ and $12,000 \mathrm{xg}$ for 
$30 \mathrm{~min}$, the supernatant was obtained and mixed with an equal volume of isopropanol. RNA pellets were precipitated by centrifugation at $4{ }^{\circ} \mathrm{C}$ and $12,000 \times g$ for $30 \mathrm{~min}$. Pellets were then washed with $70 \%$ alcohol, and stored at $-20{ }^{\circ} \mathrm{C}$ until use. The total RNA samples were purified using an RNeasy Mini Kit (Qiagen, Huntsville, AL), and treated with DNase1 to remove genomic DNA. The quantity and quality of total RNA were assessed by Nanodrop spectrophotometry (ND-1000, NanoDrop Technology, Wilmington, DE) and agarose gel electrophoresis, respectively.

Verification of gene expression using quantitative real-time RT-PCR. For cDNA synthesis, $5 \mu \mathrm{g}$ of total RNA was reverse-transcribed in a final volume of $20 \mu \mathrm{L}$ containing $0.5 \mathrm{mM}$ dNTPs, 2.5 $\mu \mathrm{M}$ oligo $(\mathrm{dT})_{20}, 250 \mathrm{ng}$ of random primers, $5 \mathrm{mM}$ dithiothreitol, 40 units of an RNase inhibitor, and 200 units of PowerScript reverse transcriptase (Invitrogen) for $30 \mathrm{~min}$ at $50^{\circ} \mathrm{C}$, followed by incubation at 70 ${ }^{\circ} \mathrm{C}$ for $15 \mathrm{~min}$. Twenty units of Escherichia coli RNase H (Invitrogen) were added to remove the remnant RNA in a 20 -min incubation at $37^{\circ} \mathrm{C}$. Real-time qRT-PCR was used to analyze expression of 4 transcripts: stc-1, stc-1 like, stc-2, and stc-2 like. qRT-PCR was carried out using a Roche Lightcycler 480 (Roche, Penzberg, Germany). The final volume in a well was $10 \mu \mathrm{L}$, consisting of $5 \mu \mathrm{L}$ of $2 X$ SYBR green master mix (Roche), $3.2 \mathrm{ng}$ of cDNA, and $50 \mathrm{nM}$ of primer pairs. The standard curve of each gene was checked in the linear range, with $\beta$-actin or ribosomal protein L13a (RPL13a) serving as internal controls. For the qRT-PCR experiments, similar patterns were observed irrespective of which of the 2 reference genes were used for normalization in accordance with our previous study [23]. Primers were designed using Primer Express 2.0 software (Applied Biosystems, Wellesley, MA, USA). The sequences of primer sets used are as follows: stc-1 forward 5'CCAGCTGCTTCAAAACAAACC-3', stc-1 reverse 5'-ATGGAGCGTTTTCTGGCGA-3'; stc-1 like forward 5'-CCAAGCCACTTTCCCAACAG-3', stc-1 like reverse 5'-ACCCACCACGAGTCTCCATTC-3'; stc-2 forward 5'-TATGGTCTTCCAGCTTCAGCG-3', stc-2 reverse 5'-CGAGTAATGGCTTCCTTCACCT-3'; stc-2 like forward 5'-CCGTCCCAGATGTCACTACCAC-3'; stc-2 like reverse 5'-TCTGCAGAGACAGTCTTTTCTT GTG-3'; foxi3a forward 5'-CTCTCGCTCAATGACTG CTTC-3'; foxi3a reverse 5'-CAGCCTGAGAGTCC GACTTTC-3'; atp6v1a forward 5'-GAGGAACCACTG CCATTCCA-3'; atp6v1a reverse 5'-CAACCCACATA AATGATGACATC-3'; trpv6 forward 5'-TCCTTTCCC ATCACCCTCT-3'; trpv6 reverse 5'-GCACTGTGGC AACTTTCGT-3'; slc12a10.2 forward 5'-GCCCCCAA AGTTTTCCAGTT-3'; slc12a10.2 reverse 5'-TAAGC ACGAAGAGGCTCCTTG-3'.
Translational knockdown with antisense morpholino oligonucleotides. Morpholino-modified antisense oligonucleotides (MOs) were purchased from Gene Tools (Philomath, OR). The stc-1 and foxi3a MOs were designed to be complementary to the ATG region for translation inhibition. The maximal dosage used that caused no obvious toxic effects on embryogenesis was as follows: stc- 1 MO (5'-AAATCC GCTTTTCAGGAGCATGTCT-3') at $1.3 \mathrm{ng} / \mathrm{embryo;}$ mismatched stc-1 MO (5'-AAATGCCCTTTTG AGGACCATCTCT-3') at $1.3 \mathrm{ng} /$ embryo; foxi3a $\mathrm{MO}$ (5'-TCTTCCCGTTTCTCTTTGTTGAAGG-3') at 4 ng/embryo; and mismatched foxi3a MO (5'TCATGCCCTTTCTGTTTCTTGAAGG-3') at 4 ng/embryo. The specificity and efficiency of MOs were tested and confirmed by previous studies $[3,31]$. The MOs were prepared with $1 \times$ Danieau solution (58 $\mathrm{mM} \mathrm{NaCl}, 0.7 \mathrm{mM} \mathrm{KCl}, 0.4 \mathrm{mM} \mathrm{MgSO}, 0.6 \mathrm{mM}$ $\mathrm{Ca}\left(\mathrm{NO}_{3}\right)_{2}$, and $5.0 \mathrm{mM}$ HEPES; $\mathrm{pH}$ 7.6). MO solution was injected into zebrafish embryos at the 1 2-cell stage using an IM-300 microinjector system (Narishigi Scientific Instrument Laboratory, Tokyo, Japan).

Plasmid construction. To generate the pCS2 ${ }^{+}$-zSTC- 1 and pCS2 ${ }^{+}$-Fxoi3a constructs, the corresponding zebrafish stc-1 (747 bp) and foxi3a (1153 bp) coding regions were amplified by PCR using the following pairs of primers: stc-1 forward 5'-GGATCCATGCTCCTGAAAAGCGGCTTTCTT-3', stc-1 reverse 5'-GAATCCAGGACTTCCCACGATG GAGCGTTT-3', foxi3a forward 5'-AAAGAATTCC GGGAAGAAAGCATG-3', and foxi3a reverse 5'-TGTCTCGAGTTACACCTCAGATCCC-3'. The zSTC-1 and Foxi3a PCR amplicons were cloned into a pGEM-T easy vector (Promega, Madison, WI) using BamHI and EcoRI sites, and was then subcloned into a $\mathrm{pCS}^{+}$vector using the BamHI and EcoRI sites.

Capped-mRNA injection. The constructs cloned into the $\mathrm{pCS}^{+}$vectors were linearized using NarI, and capped-mRNA was transcribed using an SP6 message RNA polymerase kit (Ambion, Huntington, UK). Capped-mRNAs were injected into embryos at the 1-cell stage at a dose of $40 \mathrm{pg} /$ embryo for STC-1 and $50 \mathrm{pg} /$ embryo for Foxi3a. The efficiency of capped-mRNA (cRNA) was tested and confirmed in a previous study $[3,31]$.

Measurement of whole-body $\mathrm{Na}^{+}, \mathrm{Ca}^{2+}$, and $\mathrm{Cl}^{-}$ contents. Fifteen zebrafish larvae were rinsed by deionized water several times and then pooled as one sample. $\mathrm{HNO}_{3}$ at $13.1 \mathrm{~N}$ was added to the samples for digestion at $60^{\circ} \mathrm{C}$ overnight. After digestion the samples were diluted with double-deionized water, and the total $\mathrm{Na}^{+}$and $\mathrm{Ca}^{2+}$ contents were measured by atomic absorption spectrophotometry (Z-8000; Hitachi, Tokyo, Japan). For $\mathrm{Cl}^{-}$content measurements, fifteen zebrafish larvae were homogenized with $1 \mathrm{~mL}$ 
deionized water and then centrifuged at $14,000 \mathrm{rpm}$ for $30 \mathrm{~min}$. After collecting the supernatant from each sample, $\mathrm{Hg}\left(\mathrm{SCN}_{4}\right)_{2} \quad(0.3 \mathrm{~g}$ in $95 \%$ ethanol $)$ and $\mathrm{NH}_{4} \mathrm{Fe}\left(\mathrm{SO}_{4}\right)_{2} \cdot 12 \mathrm{H}_{2} \mathrm{O}\left(30 \mathrm{~g}\right.$ in $135 \mathrm{~mL} 6 \mathrm{~N} \mathrm{HNO}_{3}$ ) solutions were added for the analysis. The $\mathrm{Cl}^{-}$concentration was measured by the ferricyanide method with a double-beam spectrophotometer (model U-2000; Hitachi). The standard solutions of $\mathrm{Na}^{+}, \mathrm{Ca}^{2+}$, and $\mathrm{Cl}^{-}$from Merck (Darmstadt, Germany) were used to make the standard curves.

Measurement of surface $\mathrm{pH}$ of zebrafish embryos. Proton secretion in zebrafish embryos was determined by measuring the $\mathrm{pH}$ at the yolk surface. A noninvasive scanning $\mathrm{H}^{+}$-selective electrode technique (SIET) was used to measure extracellular $\mathrm{H}^{+}$ activity $(\mathrm{pH})$ at the surface of zebrafish embryos, as previously described $[35,36]$. Briefly, microelectrodes with a tip diameter of 3-4 $\mu \mathrm{m}$ were pulled from glass capillary tubes (P-97 Flaming Brown pipette puller, Sutter Instruments), then were baked at $200^{\circ} \mathrm{C}$ overnight, and vapor-silanized with dimethylchlorosilane (Fluka) for $30 \mathrm{~min}$. The microelectrodes were backfilled with $100 \mathrm{mM} \mathrm{KCl} / \mathrm{H}_{2} \mathrm{PO}_{4}(\mathrm{pH} 7.0)$, and then were frontloaded with a 20- to $30-\mu \mathrm{m}$ column of liquid ion exchanger cocktail (hydrogen ionophore I-cocktail B; Fluka). The $\mathrm{H}^{+}$microelectrode was positioned with a step-motor-driven 3-dimensional positioner (Applicable Electronics) via an $\mathrm{Ag} / \mathrm{AgCl}$ wire electrode holder (World Precision Instruments), and the circuit was completed by placing a salt bridge (an $\mathrm{Ag} / \mathrm{AgCl}$ wire-connected capillary tube that is filled with 3\% agarose containing $3 \mathrm{M} \mathrm{KCl}$ ). Data acquisition, preliminary processing, and control of the 3-dimensional electrode positioner were performed with ASET software (Science Wares). The microelectrode system was attached to an Olympus upright microscope (BX-50WI). The Nernstian properties of each microelectrode were measured by placing the microelectrode in a series of standard $\mathrm{pH}$ solutions $(\mathrm{pH} 6,7$, and 8). To detect surface $\mathrm{H}^{+}$activity of zebrafish embryos, SIET was performed at room temperature in a small plastic recording chamber filled with $1 \mathrm{~mL}$ of recording solution, which consisted of artificial media (0.4-0.6 mM NaCl, $0.18-0.20 \mathrm{mM} \mathrm{CaSO}_{4}, 0.18-0.20 \mathrm{mM}$ $\mathrm{MgSO}_{4}, 0.05-0.06 \mathrm{mM} \mathrm{KH} \mathrm{PO}_{4}$, and $0.05-0.06 \mathrm{mM}$ $\mathrm{K}_{2} \mathrm{HPO}_{4}$ ), $300 \mu \mathrm{M}$ MOPS buffer (Sigma), and $0.1 \mathrm{mg} / 1$ tricaine (3-aminobenzoic acid ethyl ester; Sigma; $\mathrm{pH}$ 6.8). An anesthetized embryo was positioned in the center of the chamber, with its lateral side contacting the base of the chamber; it remained in that position for $3 \mathrm{~min}$. The probe was then moved to a target position on the skin surface of the yolk sac and used to take recordings for 30 seconds; it was subsequently moved approximately $1 \mathrm{~cm}$ away from the embryo to record background levels in the media. The voltage outputs were converted to $\mathrm{H}^{+}$concentrations according to the 3-point calibration curve, and $\Delta\left[\mathrm{H}^{+}\right]$was used to represent the $\mathrm{H}^{+}$gradients between the target point on the skin surface and the background.

Whole-mount in situ hybridization. Fragments of foxi3 $a$ were obtained by PCR and inserted into the pGEM-T easy vector (Promega, Madison, WI). The inserted fragments were amplified with the T7 and SP6 primers by PCR, and the products used as templates for in vitro transcription with T7 and SP6 RNA polymerase (Roche) in the presence of digoxigenin (DIG)-UTP (Roche), to synthesize sense and anti-sense probes, respectively. DIG-labeled RNA probes were examined using RNA gels, and a dot blot assay was used to confirm their quality and concentrations. Zebrafish embryos were anesthetized on ice, and fixed with $4 \%$ paraformaldehyde in a phosphate-buffered saline (PBS; $1.4 \mathrm{mM} \mathrm{NaCl}, 0.2 \mathrm{mM}$ $\mathrm{KCl}, 0.1 \mathrm{mM} \mathrm{Na} 2 \mathrm{HPO}_{4}$, and $0.002 \mathrm{mM} \mathrm{KH}_{2} \mathrm{PO}_{4} ; \mathrm{pH}$ 7.4) solution at $4{ }^{\circ} \mathrm{C}$ overnight. Afterwards, samples were washed with diethylpyrocarbonate -treated PBST (PBS with 0.1\% Tween-20) several times (10 $\mathrm{min} /$ wash). After washing, samples were first incubated with hybridization buffer (HyB, 50\% formamide, $5 \times$ SSC, and $0.1 \%$ Tween 20) at $65^{\circ} \mathrm{C}$ for $5 \mathrm{~min}$, and subsequently with $\mathrm{HyB}$ containing $500 \mu \mathrm{g} / \mathrm{mL}$ yeast tRNA at $65^{\circ} \mathrm{C}$ for $4 \mathrm{~h}$ before hybridization. After overnight hybridization with $100 \mathrm{ng} / \mathrm{mL}$ DIG-labeled antisense or sense RNA probes, embryos were serially washed with $50 \%$ formamide-2x SSC (at $65^{\circ} \mathrm{C}$ for 20 min), $2 \times$ SSC (at $65^{\circ} \mathrm{C}$ for $10 \mathrm{~min}$ ), $2 \times$ SSC (at $65^{\circ} \mathrm{C}$ for $10 \mathrm{~min}$ ), $0.2 \times \mathrm{SSC}$ (at $65^{\circ} \mathrm{C}$ for $30 \mathrm{~min}, 2$ times), and PBST at room temperature for $10 \mathrm{~min}$. Embryos were then immunoreacted with an alkaline phosphatase-coupled anti-Dig antibody (1: 8000), and stained with nitro blue tetrazolium (Roche) and 5-bromo-4-chloro-3-indolyl phosphate (Roche) for the alkaline phosphatase reaction. For quantification, the cell densities in the yolk sac skin of embryos were analyzed using freehand selections of image processing program (ImageJ 1.45s; Wayne Rasband, $\mathrm{NIH}$ ). The total area of the yolk sac (one side for each embryo) was calculated by the image program based on the designated scale bar size of the image acquired from the microscope.

Whole-mount immunohistochemistry. Embryos from different developmental stages were fixed in $4 \%$ paraformaldehyde in PBST. For keratin antibody staining, embryos were fixed in Dent's fixative $(80 \%$ methanol and $20 \%$ DMSO) at $-20{ }^{\circ} \mathrm{C}$ for $1 \mathrm{~h}$. Samples were then incubated with $3 \%$ bovine serum albumin for $2 \mathrm{~h}$ to block nonspecific binding, before being incubated at $4{ }^{\circ} \mathrm{C}$ overnight with either: an a5 monoclonal antibody against the a-subunit of the avian $\mathrm{Na}^{+}-\mathrm{K}^{+}$-ATPase (Developmental Studies Hybridoma 
Bank, University of Iowa, Ames, IA); a polyclonal antibody against the A subunit of zebrafish $\mathrm{H}^{+}$-ATPase (synthetic peptide: AEMPADSGYPAYLG ARLA) (30); a polyclonal antibody against the $\mathrm{N}$-terminal domain of zebrafish $\mathrm{Na}^{+}-\mathrm{Cl}^{-}$cotransporter like 2 (synthetic peptide: IKKSRPSLDVLRNPPDD) (34); a monoclonal antibody against keratin type 2 (PROGEN Biotechnik, Heidelberg, Germany); or a monoclonal antibody against human P63 (Santa Cruz Biotechnology, Santa Cruz, CA). After washing with PBST for $20 \mathrm{~min}$, samples were further incubated with Alexa Fluor 488 goat anti-rabbit immunoglobulin (IgG) (Molecular Probes, Carlsbad, CA; 1: 200 dilution with PBS) or an Alexa Fluor 568 goat anti-mouse IgG antibody (Molecular Probes; 1: 200 dilution with PBST) for $2 \mathrm{~h}$ at room temperature. Images
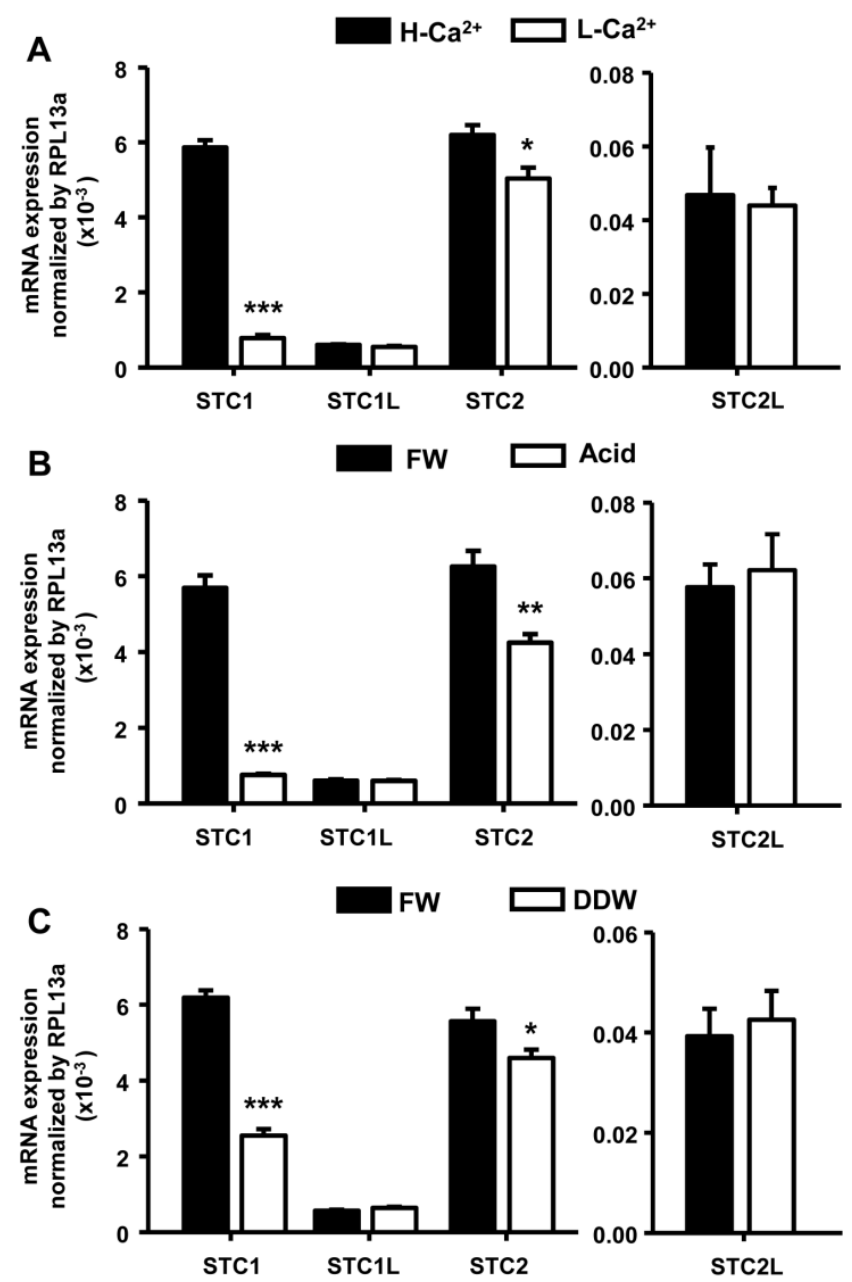

Figure 1. Different environments affect expression of STC genes in zebrafish embryos. Zebrafish embryos were incubated with high-Ca ${ }^{2+}$ or acidic $(\mathrm{pH}=4)$ media for $4 \mathrm{~d}$ or double-deionized water for $1 \mathrm{~d}$, and the mRNA levels of four STC genes were then measured by qRT-PCR. (A) stc-l (STC1) and stc-2 (STC2) mRNAs were significantly decreased by low-Ca ${ }^{2+}(A)$, acidic $(B)$ and double-deionized water (DDW)(C) treatments, while that of stc-l like (STC1L) and stc-2 like (STC2L) were unaffected. Low-Ca ${ }^{2+}(A)$, acidic $(B)$ and double-deionized water $(C)$ treatments caused greater reductions of stc- $I$ mRNA ( $87 \%, 87 \%$ and $60 \%$, respectively) than stc- 2 mRNA $(17 \%, 32 \%$ and $17 \%$, respectively). qRT-PCR values were normalized to that of rpll 3a. Mean \pm SEM $(n=4-5)$. $(p<0.05)$, ** $(p<0.01)$ or $* * *(p<0.001)$ indicates a significant difference from the control (Student's t-test,). were acquired with a Leica TCS-SP5 confocal laser scanning microscope (Leica Lasertechnik, Heidelberg, Germany). Cell density quantification was performed as described above.

Statistical analysis. Values are presented as the mean \pm SEM, and were compared using Student's $t$-test or Chi-square test.

\section{Results}

\section{Expression of stc genes in zebrafish embryos under different environments}

Sequence information for four STC isoforms (stc-1, stc-1 like, stc-2, and stc-2 like) was obtained from the Ensembl database. To examine environmental effects on the expression of stc genes, we incubated embryos under different conditions (high- $\mathrm{Ca}^{2+}$ or acidic treatment for $4 \mathrm{~d}$, or double-deionized water treatment for $1 \mathrm{~d}$ ), and then measured gene expression levels by qRT-PCR. stc-1 mRNA was significantly decreased by low- $\mathrm{Ca}^{2+}$, acidic, and double-deionized environments (Fig. 1). stc-2 mRNA was also affected by the artificial media with a similar pattern, but the effects were milder compared to that on stc-1 (Fig. 1A). No significant difference was found for stc-1 like and stc-2 like mRNA under any treatments (Fig. 1). Although we found a significant decrease in the level of $s t c-2$ mRNA (about 17-33\%) under acidic and hypotonic treatments compared to freshwater control, the difference was much less than that in stc-1 mRNA (about $60-87 \%$ ); this suggests that STC-1, instead of STC-2, plays a major role in ion balance in zebrafish embryo. Therefore, we focused on the function and actions of STC-1 in the following experiments.

\section{STC-1 regulates the functions of ionocytes}

Our results indicate that stc-1 expression negatively correlates with the functions of ionocyts (Fig. 1); we next performed overexpression experiments to investigate the effects of STC- 1 on ion regulation functions in zebrafish embryos. The embryos were injected with stc- 1 cRNA (40 pg/embryo) and incubated in double-deionized water for the hypotonic challenge for $72 \mathrm{~h}$, and then the mortality and morphologies of embryos were observed. The stc- 1 cRNA injected embryos showed higher mortality (32\%) and malformation phenotypes (29\%) than control embryos (10\% mortality and 5\% malformation phenotypes; Chi-square test, $p<0.0005$ ) (Table 1), indicating that overexpression of stc-1 impairs the hypotonic acclimation in zebrafish embryos. We then measured the whole-body contents of $\mathrm{Ca}^{2+}, \mathrm{Na}^{+}$, and $\mathrm{Cl}^{-}$ions and the $\mathrm{H}^{+}$secretion of zebrafish embryos that were incubated in fresh water for $72 \mathrm{~h}$. Overexpression of stc- 1 caused a significant decrease of the whole-body 
$\mathrm{Ca}^{2+}, \mathrm{Na}^{+}$, and $\mathrm{Cl}^{-}$ion contents in stc- 1 cRNA injected embryos compared to those in control embryos (Fig. 2A). The stc-1 cRNA injected embryos also showed a lower $\mathrm{H}^{+}$secretion ability than control embryos (Fig. 2B). Moreover, the mRNA expressions of three ion transporters, ECaC, $\mathrm{H}^{+}$-ATPase, and $\mathrm{Na}^{+}-\mathrm{Cl}^{-}$cotransporter (NC), were significantly suppressed by stc-1 cRNA injection at 2- and 3-d post fertilization (dpf) (Fig. 3). These results demonstrate that STC-1 regulates ionocyte functions in a negative manner.
Table 1. Effects of stc-I cRNA injection on the hypotonic acclimation in zebrafish embryos.

\begin{tabular}{lllll}
\hline Treatment & Survival rate $(\%)$ & \multicolumn{3}{l}{ Percentage of different phenotypes } \\
\hline & & Normal & Malformation & Death \\
Control & 90 & 85 & 5 & 10 \\
stc-1 cRNA & $68^{*}$ & 49 & 29 & 32
\end{tabular}

One-cell stage embryos were injected with the STC-1 cRNA and incubated in double deionized (dd) water for $72 \mathrm{~h}$, and the mortality and morphologies of embryos were observed. $1 x$ Danieau solution (Control) was used as controls. In each treatment, 100 embryos were analyzed. * Significant difference $\left(\chi^{2}\right.$ test, $p<0.0005)$ from control.
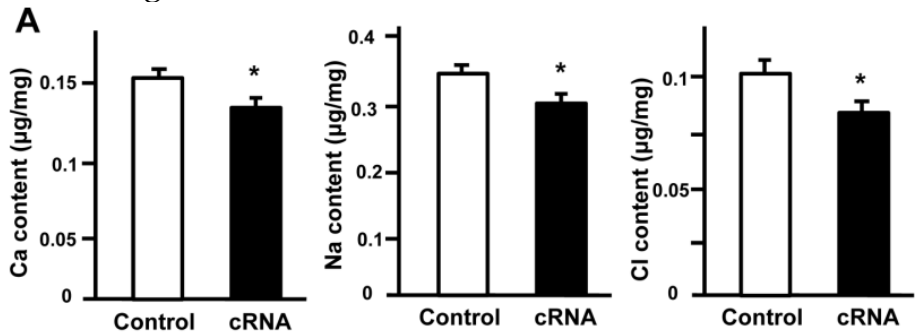

B

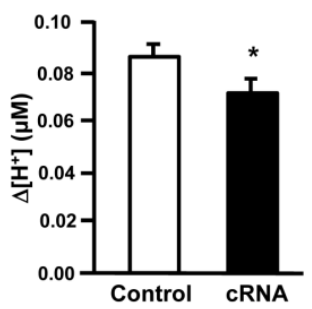

Figure 2. STC- 1 regulates the functions of ionocytes. The embryos were injected with stc- $\mathrm{cRNA}\left(40\right.$ pg/embryo) and the whole-body contents of $\mathrm{Ca}{ }^{2+}, \mathrm{Na}^{+}$, and $\mathrm{Cl}^{-}$ions and the $\mathrm{H}^{+}$secretion of zebrafish embryos that were incubated in fresh water for $72 \mathrm{~h}$. Overexpression of stc- $\mathrm{I}$ caused a significant decrease of whole-body $\mathrm{Ca}{ }^{2+}$, $\mathrm{Na}^{+}$, and $\mathrm{Cl}^{-}$ ion contents in stc- $I$ cRNA injected embryos compared to those in control embryos injected with $1 \times$ Danieau solution (A). The stc- $I$ cRNA injected embryos also showed a lower $\mathrm{H}^{+}$secretion ability than control embryos $(B)$. Mean \pm SEM $(n=13-16) . *$ Indicates a significant difference from the control (Student's $t$-test, $\left.p<0.05\right)$.

cRNA $\square$ Control
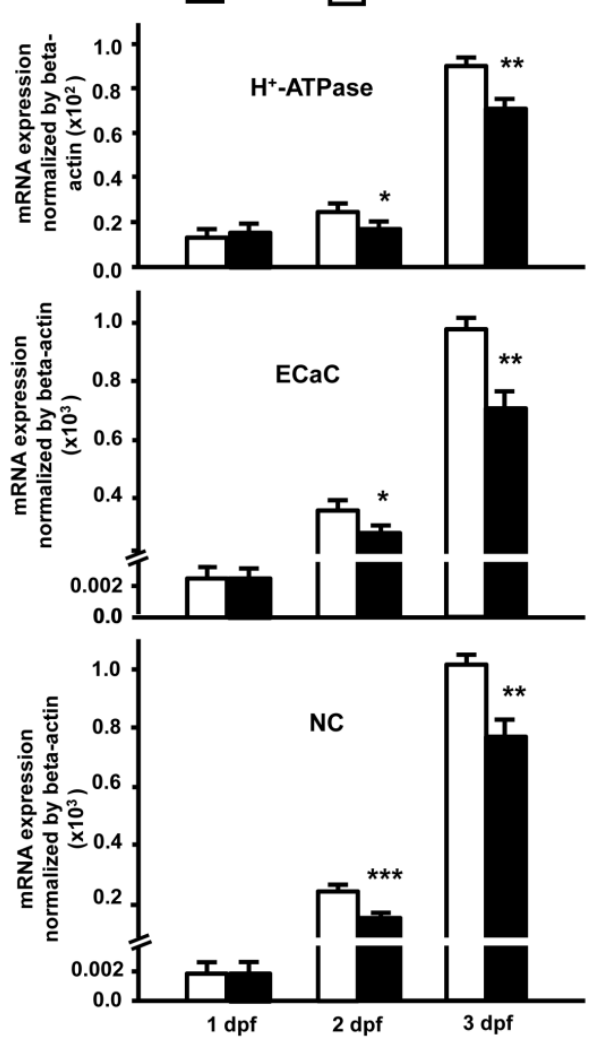

Figure 3. STC-1 suppresses the mRNA expressions of ion transporter genes. One-cell stage embryos were injected with stc-l cRNA (40 pg/embryo) and the mRNA expressions of atp6rla ( $\mathrm{H}^{+}$-ATPase), trpv6 (ECaC), and slcl $2 a 10.2$ (NC) were analyzed by qRT-PCR. The gene expressions of three ion transporters in stc-l cRNA injected embryos showed similar levels compared with control embryos injected with $1 \times$ Danieau solution at $1 \mathrm{dpf}$, but were significantly down-regulated at 2 and 3 dpf. qRT-PCR values were normalized to that of beta-actin. Mean \pm SEM $(n=$ $4-5) . *(p<0.05), * *(p<0.01)$ or $* * *(p<0.001)$ indicates a significant difference from the control (Student's t-test,).

\section{STC-1 negatively modulates the number of ionocytes in zebrafish skin}

To examine if the of STC- 1 affects the cell densities of ionocytes in zebrafish embryo skin, we manipulated STC-1 protein expression, and observed the resulting effects on 3 subtypes of skin ionocytes: $\mathrm{Na}^{+}-\mathrm{K}^{+}$-ATPase-rich (NaR), $\mathrm{H}^{+}$-ATPase-rich (HR), and $\mathrm{Na}^{+}-\mathrm{Cl}^{-}$cotransporter (NC) cells (responsible for $\mathrm{Ca}^{2+}$ uptake, $\mathrm{H}^{+}$secretion/ $\mathrm{Na}^{+}$uptake $/ \mathrm{NH}_{4}{ }^{+}$excretion, and $\mathrm{Na}^{+}$uptake/Cl- uptake, respectively) [33-39]. The STC-1 MO caused $26 \%, 27 \%$, and $35 \%$ increases in the numbers of NaR, HR, and NC cells, respectively (Fig. $4 A-G)$. In contrast, injection of stc-1 cRNA caused $20 \%, 28 \%$, and $26 \%$ decreases in the three types of cells (Fig. 4H-N). Our previous results have shown that around $20-30 \%$ changes in ionocyte numbers is sufficient to affect the ion regulation functions [23], hence the changes of cell densities that were resulted 
from manipulation of STC-1 protein expression in the present study have the biological and functional significances. Furthermore, in situ hybridization and qRT-PCR analysis revealed that the number of cells expressing foxi3a (which encodes the master regulator of ionocyte differentiation in zebrafish [31] and the foxi3a mRNA expression at the tail-bud stage (which
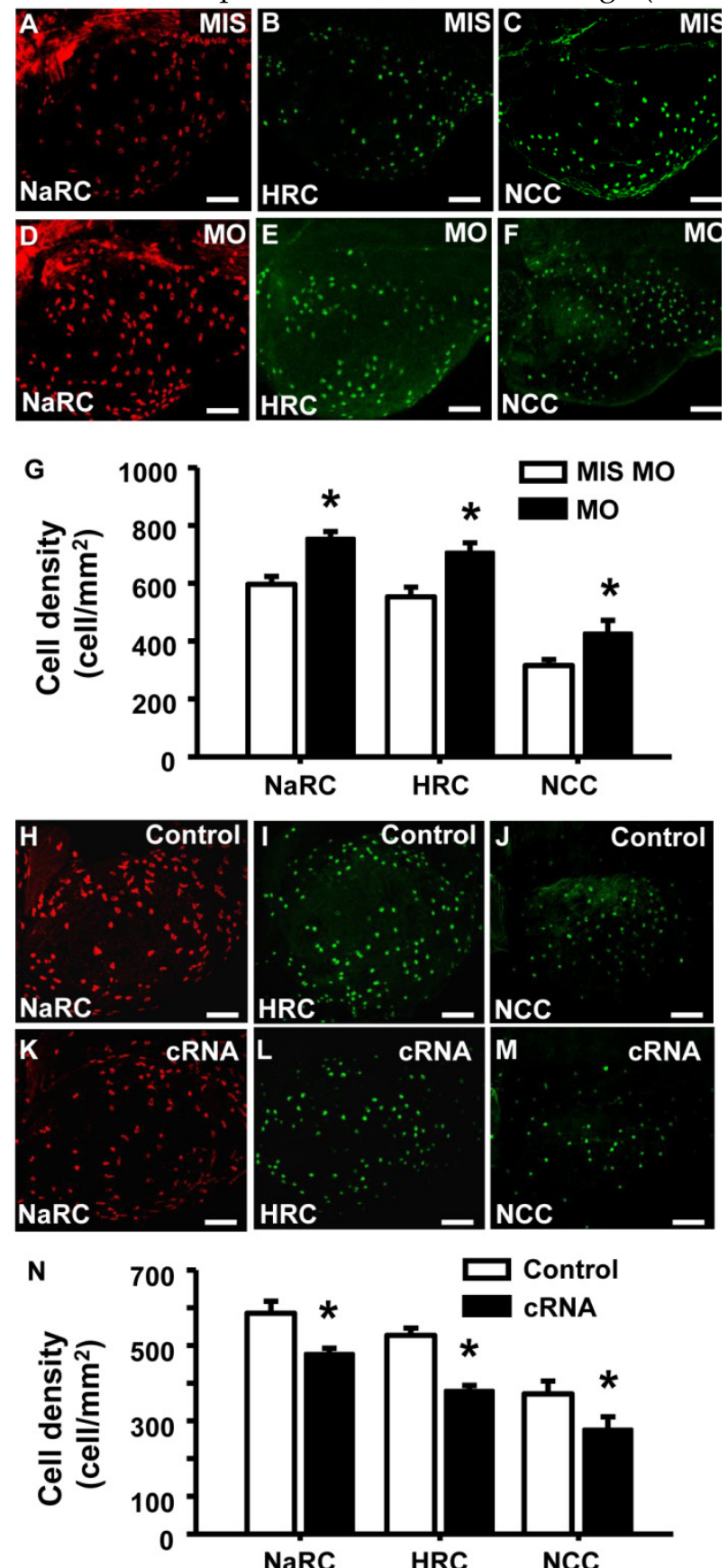

Figure 4. STC-1 negatively modulates the number of ionocytes in zebrafish skin. One-cell stage embryos were injected with either an stc-I morpholino (MO) (1.3 ng/embryo) or stc-l cRNA (40 pg/embryo). NaR cells ( $\mathrm{NaRC}$ ). HR cells (HRC), and NC cells (NCC) were subsequently detected at 72 hpf, by antibody labeling of $\mathrm{Na}^{+}-\mathrm{K}^{+}$-ATPase, $\mathrm{H}^{+}$-ATPase, and $\mathrm{Na}^{+}-\mathrm{Cl}-$ cotransporter, respectively. Mismatched-MO (MIS) and 1x Danieau solution (control) were used as controls. $\mathrm{NaRC}, \mathrm{HRC}$, and NC cell density in the yolk sac skin of embryos were significantly higher in stc-l morphants (the embryos injected with $\mathrm{MO}$ ) than in mismatched-MO-injected embryos (A-G). stc-I cRNA injection significantly decreased ionocyte cell densities $(\mathrm{H}-\mathrm{N})$. Mean $\pm \operatorname{SEM}(n=12)$ * Indicates a significant difference from the control (Student's $t$-test, $p<0.05$ ). Scale bar, $100 \mu \mathrm{m}$. is prior to ion transporter gene expression) were increased by stc-1 MO (Fig. 5A-D), but decreased by stc-1 cRNA (Fig. 5E-H). Collectively, these results indicate that STC-1 negatively regulates the number of ionocytes, probably through the transcription regulation of foxi3a mRNA.
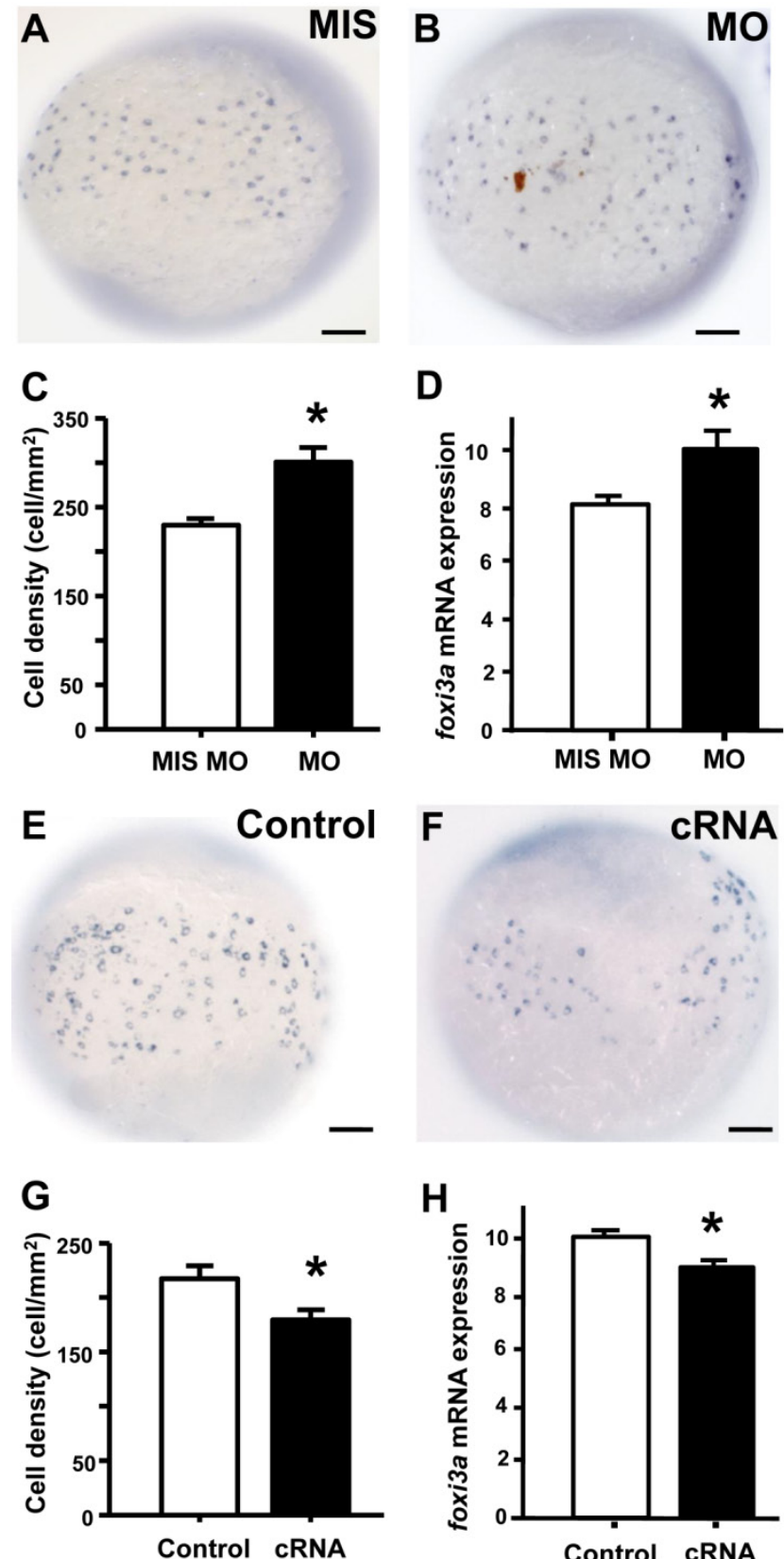

H

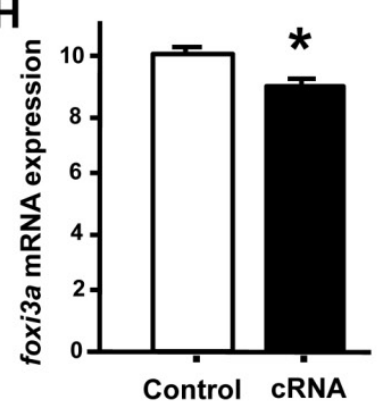

Figure 5. STC-1 negatively regulates foxi3a expression at the tail-bud stage. One-cell stage embryos were injected with an stc-I morpholino (MO) (1.3 ng/embryo) or stc-I cRNA (40 pg/embryo), and foxi3a mRNA was subsequently detected using in situ hybridization and qRT-PCR at the tail-bud stage. Mismatched$\mathrm{MO}$ (MIS) and 1x Danieau solution (Control) were used as controls. The number of foxi3a-expressing cells in the surface of yolk and foxi3a mRNA expression were significantly increased by stc-I MO (A-D), and significantly decreased by stc-I cRNA $(E-H)$. qRT-PCR values were normalized to that of beta-actin. Mean $\pm \operatorname{SEM}(n=10$ or 6). * Indicates a significant difference from the control (Student's $t$-test, $p<0.05$ ). Scale bar, $100 \mu \mathrm{m}$. 

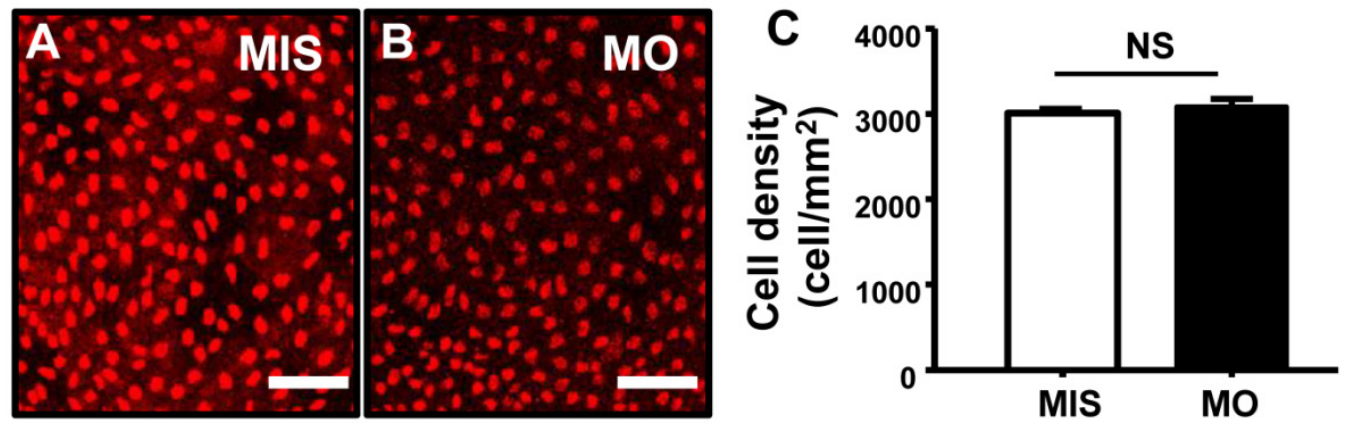

Figure 6. STC-1 does not affect epidermal stem cells. One-cell stage embryos were injected with an STC-1 morpholino (MO) (1.3 ng/embryo) and epidermis stem cells were subsequently detected by antibody labeling. The densities of epidermis stem cells (A-C) in the central part of yolk sac skin were unaffected by STC-1 MO (Student's $t$-test, $p<0.05)$. Mean \pm SEM $(n=5)$. MIS, mismatched MO. NS, non-significance; Scale bar, $50 \mu \mathrm{m}$.

\section{STC-1 does not affect epidermal stem cells}

P63 is a marker of epidermal stem cells, which have been demonstrated to differentiate into skin ionocytes and keratinocytes in zebrafish [40]. As shown in Fig. 6, the densities of P63+ cells (Fig. 6A-C) were unaffected in STC-1 morphants (control 3009 \pm 45 vs. morphant $3084 \pm 102$ cell $\left./ \mathrm{mm}^{2} ; p=0.496\right)$. No differences in the cell densities of epidermal stem cells were found between wild type and mismatched MO-injected embryos (data not shown).

\section{Discussion}

Our study reveals that STC-1 not only functions as a hypocalcemic peptide, but also participates in the balance of acid/base and other ions. STC-1 suppresses the expression of foxi3a and also affects the density of ionocytes in ion-transporting epithelium via transcriptional regulation of foxi3a expression to maintain body fluid ionic homeostasis. Thus, STC-1 appears to control transepithelial ion transport by regulating cell differentiation, rather than regulating the affinities or activities of ion transporters themselves.

STC-1 was originally described as a calcitonin-like hormone in fish. Surgical removal of the corpuscles of Stannius gland from European eel causes hypercalcemia, demonstrating the hypocalcemic actions of STC- 1 [41]. STC-1 is released into the bloodstream, and reduces $\mathrm{Ca}^{2+}$ uptake in both gills and intestines [42]. In mammals, STC-1 was also found to regulate the $\mathrm{Ca}^{2+}$ balance by mediating intestinal $\mathrm{Ca}^{2+}$ and phosphate transport [6]. However, recent studies in both fish and mammals have suggested that STC-1 is also involved in the balance of other ions in body fluids $[4,5,8,43]$. This hypothesis is supported by our acclimation experiments. Of the stc family members, only stc-1 mRNA expression was majorly affected by changes in environmental conditions (Fig.1); furthermore, these environmental conditions were previously reported to stimulate ion transport functions that are not confined to $\mathrm{Ca}^{2+}$ uptake in zebrafish [44].
According to the current model of zebrafish ion regulatory mechanisms $[29,32]$, the 3 main types of ionocytes, $\mathrm{NaR}, \mathrm{HR}$ and $\mathrm{NC}$ cells, are responsible for $\mathrm{Ca}^{2+}$ uptake, $\mathrm{Na}^{+}$uptake/ $\mathrm{H}^{+}$secretion, and $\mathrm{Na}^{+}$uptake $/ \mathrm{Cl}^{-}$ uptake, respectively, and the key transporters are $\mathrm{ECaC}, \mathrm{H}^{+}$-ATPase, and $\mathrm{NC}$ in the 3 types of ionocytes. The physiological experiments showed that overexpression of stc- 1 impaired the hypotonic acclimation by decreasing whole body $\mathrm{Ca}^{2+}, \mathrm{Na}^{+}$, and $\mathrm{Cl}^{-}$contents and the $\mathrm{H}^{+}$secretion ability (Fig. 2). In addition, stc-1 suppressed the mRNA expressions of ion transporter genes that are crucial for the functions of ion balance for zebrafish (Fig. 3). These observations support the notion that STC-1 is not restricted to its role as a hypocalcemic peptide, but also helps regulate the balance of other ions.

Due to a lack of information pertaining to the STC-1 receptor, the mechanisms by which STC-1 regulates ion balance, and the identity of its target cells/genes, remain unclear. Heijden and colleagues performed stanniectomy on eels, and found that while transepithelial $\mathrm{Ca}^{2+}$ influx in the gills increased, the membrane density and affinity of $\mathrm{Ca}^{2+}$ transporters remained unaffected [45]. They speculated that the increase in $\mathrm{Ca}^{2+}$-transporting capacity may have arisen from an increase in the number and/or size of $\mathrm{Ca}^{2+}$-transporting cells, but no evidence was presented to support this hypothesis. Our previous study in zebrafish demonstrated that STC-1 negatively regulates expression of epithelial $\mathrm{Ca}^{2+}$ channels, thereby reducing $\mathrm{Ca}^{2+}$ influx and whole body $\mathrm{Ca}^{2+}$ content [3]. However, these data did not exclude the possibility that STC-1 modulates the number of ionocytes, the main cell type through which ion balance is regulated. In the present study, we clearly demonstrate a relationship between STC-1 expression and the number of ionocytes. The density of ionocytes was increased by stc-1 knockdown and decreased by stc- 1 overexpression (Fig. 4). The inverse relationship between stc-1 expression and ionocyte density suggests that STC-1 negatively regulates the number of ionocytes, since 
changing the numbers of ionocytes was known to result in the modulation of ionocyte's functions [33, 44, 46]. This finding is intriguing, because it addresses long-term unsolved questions, thereby providing new insights into the role of STC- 1 in controlling transepithelial ion transport.

Two possible pathways were proposed to control the numbers of ionocytes in zebrafish skin: regulation of ionocyte precursor differentiation and/or regulation of epidermal stem cell proliferation [30, 32, $46,47]$. In order to investigate how STC- 1 regulates ionocyte number, we examined the effects of STC-1 on Foxi3a, a helix/forkhead box transcription factor which functions as a cell fate determinant [48]. Zebrafish Foxi3a is a master regulator of ionocyte differentiation [31, 49-51], and regulation of Foxi3a affects the number of mature ionocytes [23,51]. At the tail-bud stage, zebrafish embryos express foxi3a, but not the mature ionocyte markers atp $1 b 1 b$ or atp6v1a, indicating that only ionocyte precursor cells exist at this stage [31]. In the present study, manipulation of STC-1 protein expression modified foxi3a expression at the tail-bud stage (Fig. 5). The number of foxi3a-expressing cells and foxi3a mRNA expression were significantly increased by stc- $1 \mathrm{MO}$, but was significantly decreased by stc-1 cRNA; indicating that STC-1 negatively regulates the formation of ionocytes from precursor cells. Our study provides the first convincing line of evidence in support of STC-1 acting as a negative regulator for ionocyte differentiation by inhibiting foxi3a expression.

Studies in mammals have revealed that STC- 1 is involved in the regulation of cell growth and differentiation. STC-1 was reported to have both positive and negative effects, depending on context. During embryonic development, STC-1 was first expressed in mesenchymal condensations, before extending to perichondrial cells, periosteal cells, and finally, the osteoblasts [52]. This time- and cell-specific pattern of expression suggested a role for STC-1 in osteoblast development and bone formation. An in vitro study using a rat calvaria cell culture system also demonstrated that STC-1 accelerates osteoblast development [53]. Treatment of 3T3-L1 cells with an adipogenic cocktail induced their differentiation into mature adipocytes, accompanied by an increase in STC- 1 expression [20]. Up-regulation of stc mRNA levels was also reported to be accompanied by a concomitant increase in an axon-specific, low molecular form of microtubule-associated protein mRNA, suggesting a possible role for STC in axonogenesis and neural differentiation [54]. On the other hand, STC-1 has also been reported to suppress cranial intramembranous bone growth [55] and inhibit longitudinal bone growth directly at the growth plate [13]. Several ear- lier studies have demonstrated a correlation between STC-1 expression levels and the phenotypes or developmental states of cells or tissues. However, these studies failed to identify the target molecules or cells of STC-1, leaving its regulatory mechanisms unclear. Our results demonstrate that STC-1 inhibits foxi3a gene expression and negatively affects the number of ionocytes to regulate ion balance functions.

P63, a direct target of BMP signaling, is specifically expressed in non-neural ectoderm, and is involved in the induction of epidermal ectoderm specification $[39,56]$; as such, it is a marker of epidermal stem cells [31, 49]. Recent studies have reported that isotocin increases the density of skin/gill ionocytes through regulating proliferation of $\mathrm{P} 63+$ epidermal stem cells in zebrafish [23]. Based on these observations, we extended our investigation to determine if STC-1 targets P63+ cells, which are upstream of foxi3a-expressing ionocyte precursor cells. We observed no effects of stc-1 knockdown on the number of epidermal stem cells (Fig. 6A-C), suggesting that STC-1 is not involved in the regulation of epidermal stem cell proliferation. This further reinforces our notion that STC-1 is involved in regulation of body fluid ionic homeostasis by exerting its actions on ionocytes and the related transporter in transporting epithelium.

In summary, our study demonstrates that STC-1 participates in the functions of body fluid homeostasis, which are not confined to $\mathrm{Ca}^{2+}$ balance, via negatively regulating foxi3a expression to affect the number of ionocytes. The present findings provide some cues to investigate if STC-1 also mediates the similar pathway to regulate the functions of mammalian kidneys, which are analogous to zebrafish skin in terms of the expressions and functions of ion transporters $[32,44]$. In addition, the roles of STC- 1 in cell differentiation are also associated with many human physiological and disease processes, including cancers, wound healing, bone formation, and axonogenesis. As such, our study provide new insights into the broader functions of STC-1 in vertebrates and also helps elucidate mechanisms that may be valuable in the development of new disease therapies, as well as to related research fields of human health.

\section{Abbreviations}

cRNA: capped-mRNA; ECaC: epithelial calcium channel; HR: $\mathrm{H}^{+}$-ATPase-rich; MO: morpholino-modified antisense oligonucleotide; $\mathrm{NaR}$ : $\mathrm{Na}^{+}-\mathrm{K}^{+}$-ATPase-rich; $\mathrm{NC}$ : $\mathrm{Na}^{+}-\mathrm{Cl}^{-}$cotransporter; RPL13a: ribosomal protein L13a; SIET: scanning $\mathrm{H}^{+}$-selective electrode technique; STC-1: stanniocalcin-1. 


\section{Acknowledgements}

This study was financially supported by the grants to P. P. H. from Academia Sinica and the National Science Council, Taiwan, R.O.C. We extend our thanks to the Core Facilities ICOB and Taiwan Zebrafish Core Facility for the technical support during the experiments.

\section{Competing Interests}

All authors have no conflict of interest to disclose.

\section{References}

1. Roch GJ, Sherwood NM. Stanniocalcin has deep evolutionary roots in eukaryotes. Genome Biol Evol. 2011; 3: 284-94.

2. Gerritsen ME, Wagner GF. Stanniocalcin: no longer just a fish tale. Vitam Horm. 2005; 70: 105-35.

3. Tseng DY, Chou MY, Tseng YC, Hsiao CD, Huang CJ, Kaneko T, et al. Effects of stanniocalcin 1 on calcium uptake in zebrafish (Danio rerio) embryo. Am J Physiol Regul Integr Comp Physiol. 2009; 296: R549-57.

4. Pierson PM, Lamers A, Flik G, Mayer-Gostan N. The stress axis, stanniocalcin, and ion balance in rainbow trout. Gen Comp Endocrinol. 2004; 137: 263-71.

5. Hang X, Balment RJ. Stanniocalcin in the euryhaline flounder (Platichthys flesus): primary structure, tissue distribution, and response to altered salinity. Gen Comp Endocrinol. 2005; 144: 188-95.

6. Madsen KL, Tavernini MM, Yachimec C, Mendrick DL, Alfonso PJ, Buergin $\mathrm{M}$, et al. Stanniocalcin: a novel protein regulating calcium and phosphate transport across mammalian intestine. Am J Physiol. 1998; 274: G96-102.

7. Wagner GF, Vozzolo BL, Jaworski E, Haddad M, Kline RL, Olsen HS, et al. Human stanniocalcin inhibits renal phosphate excretion in the rat. J Bone Miner Res. 1997; 12: 165-71.

8. Turner J, Sazonova O, Wang H, Pozzi A, Wagner GF. Induction of the renal stanniocalcin-1 gene in rodents by water deprivation. Mol Cell Endocrinol. 2010; 328: 8-15.

9. Chang AC, Hook J, Lemckert FA, McDonald MM, Nguyen MA, Hardeman $\mathrm{EC}$, et al. The murine stanniocalcin 2 gene is a negative regulator of postnatal growth. Endocrinology. 2008; 149: 2403-10.

10. Huang L, Garcia G, Lou Y, Zhou Q, Truong LD, DiMattia G, et al. Anti-inflammatory and renal protective actions of stanniocalcin-1 in a model of anti-glomerular basement membrane glomerulonephritis. Am J Pathol. 2009; 174: 1368-78.

11. Sheikh-Hamad D. Mammalian stanniocalcin-1 activates mitochondrial antioxidant pathways: new paradigms for regulation of macrophages and endothelium. Am J Physiol Renal Physiol. 2010; 298: F248-54.

12. Liu D, Huang L, Wang Y, Wang W, Wehrens XH, Belousova T, et al. Human Stanniocalcin-1 Suppresses Angiotensin II-Induced Superoxide Generation in Cardiomyocytes through UCP3-Mediated Anti-Oxidant Pathway. PloS one. 2012; 7: e36994

13. Wu S, Yoshiko Y, De Luca F. Stanniocalcin 1 acts as a paracrine regulator of growth plate chondrogenesis. J Biol Chem. 2006; 281: 5120-7.

14. Liu G, Yang G, Chang B, Mercado-Uribe I, Huang M, Zheng J, et al. Stanniocalcin 1 and ovarian tumorigenesis. J Natl Cancer Inst. 2010; 102: 812-27.

15. Chang AC, Jellinek DA, Reddel RR. Mammalian stanniocalcins and cancer. Endocr Relat Cancer. 2003; 10: 359-73.

16. Yeung BH, Law AY, Wong CK. Evolution and roles of stanniocalcin. Mol Cell Endocrinol. 2011; 349: 272-80.

17. Koide Y, Sasaki T. Stanniocalcin-1 (STC-1) as a molecular marker for human cancer. Rinsho Byori. 2006; 54: 213-20.

18. Wascher RA, Huynh KT, Giuliano AE, Hansen NM, Singer FR, Elashoff D, et l. Stanniocalcin-1: a novel molecular blood and bone marrow marker for human breast cancer. Clin Cancer Res. 2003; 9: 1427-35.

19. He LF, Wang TT, Gao QY, Zhao GF, Huang YH, Yu LK, et al. Stanniocalcin-1 promotes tumor angiogenesis through up-regulation of VEGF in gastric cancer cells. J Biomed Sci. 2011; 18: 39.

20. Serlachius M, Andersson LC. Upregulated expression of stanniocalcin-1 during adipogenesis. Exp Cell Res. 2004; 296: 256-64.

21. Yeung $\mathrm{BH}$, Wong $\mathrm{CK}$. Stanniocalcin-1 regulates re-epithelialization in human keratinocytes. PloS one. 2011; 6: e27094.

22. Chang AC, Cha J, Koentgen F, Reddel RR. The murine stanniocalcin 1 gene is not essential for growth and development. Mol Cell Biol. 2005; 25: 10604-10.

23. Chou MY, Hung JC, Wu LC, Hwang SP, Hwang PP. Isotocin controls ion regulation through regulating ionocyte progenitor differentiation and proliferation. Cell Mol Life Sci. 2011; 68: 2797-809.

24. Lin $\mathrm{CH}$, Su CH, Tseng DY, Ding FC, Hwang PP. Action of Vitamin D and the Receptor, VDRa, in Calcium Handling in Zebrafish (Danio rerio). PloS one. 2012; 7: e45650.
25. Lafont AG, Wang YF, Chen GD, Liao BK, Tseng YC, Huang CJ, et al Involvement of calcitonin and its receptor in the control of calcium-regulating genes and calcium homeostasis in zebrafish (Danio rerio). J Bone Miner Res. 2011; 26: 1072-83

26. Lin $\mathrm{CH}$, Tsai IL, Su CH, Tseng DY, Hwang PP. Reverse effect of mammalian hypocalcemic cortisol in fish: cortisol stimulates $\mathrm{Ca}^{2+}$ uptake via glucocorticoid receptor-mediated vitamin D3 metabolism. PloS one. 2011; 6: e23689.

27. Guh YJ, Tseng YC, Yang CY, Hwang PP. Endothelin-1 regulates $\mathrm{H}^{+}$-ATPase-dependent transepithelial $\mathrm{H}^{+}$secretion in zebrafish. Endocrinology. 2014; 155: 1728-37.

28. Lin $\mathrm{CH}$, Su CH, Hwang PP. Calcium-sensing receptor mediates $\mathrm{Ca}^{2+}$ homeostasis by modulating expression of PTH and stanniocalcin. Endocrinology. 2014; 155: 56-67.

29. Hwang PP, Chou MY. Zebrafish as an animal model to study ion homeostasis. Pflugers Arch. 2013; 465: 1233-47.

30. Chang WJ, Horng JL, Yan JJ, Hsiao CD, Hwang PP. The transcription factor, glial cell missing 2, is involved in differentiation and functional regulation of $\mathrm{H}^{+}$-ATPase-rich cells in zebrafish (Danio rerio). Am J Physiol Regul Integr Comp Physiol. 2009; 296: R1192-201.

31. Hsiao CD, You MS, Guh YJ, Ma M, Jiang YJ, Hwang PP. A positive regulatory loop between foxi3a and foxi3b is essential for specification and differentiation of zebrafish epidermal ionocytes. PloS one. 2007; 2: e302.

32. Chang WJ, Hwang PP. Development of zebrafish epidermis. Birth Defects Res C Embryo Today. 2011; 93: 205-14.

33. Pan TC, Liao BK, Huang CJ, Lin LY, Hwang PP. Epithelial $\mathrm{Ca}^{2+}$ channel expression and $\mathrm{Ca}^{2+}$ uptake in developing zebrafish. Am J Physiol Regul Integr Comp Physiol. 2005; 289: R1202-11.

34. Chang WJ, Wang FF, Hu HJ, Wang JH, Lee TH, Hwang PP. Compensatory regulation of $\mathrm{Na}^{+}$absorption by $\mathrm{Na}^{+} / \mathrm{H}^{+}$exchanger and $\mathrm{Na}^{+}-\mathrm{Cl}$ - cotransporter in zebrafish (Danio rerio). Front Zool. 2013; 10:46.

35. Lin LY, Horng JL, Kunkel JG, Hwang PP. Proton pump-rich cell secretes acid in skin of zebrafish larvae. Am J Physiol Cell Physiol. 2006; 290: C371-8.

36. Horng JL, Lin LY, Huang CJ, Katoh F, Kaneko T, Hwang PP. Knockdown of V-ATPase subunit A (atp6v1a) impairs acid secretion and ion balance in zebrafish (Danio rerio). Am J Physiol Regul Integr Comp Physiol. 2007; 292: R2068-76.

37. Liao BK, Deng AN, Chen SC, Chou MY, Hwang PP. Expression and water calcium dependence of calcium transporter isoforms in zebrafish gill mitochondrion-rich cells. BMC Genomics. 2007; 8: 354.

38. Yan JJ, Chou MY, Kaneko T, Hwang PP. Gene expression of $\mathrm{Na}^{+} / \mathrm{H}^{+}$ exchanger in zebrafish $\mathrm{H}^{+}$-ATPase-rich cells during acclimation to low- $\mathrm{Na}^{+}$ and acidic environments. Am J Physiol Cell Physiol. 2007; 293: C1814-23.

39. Wang YF, Tseng YC, Yan JJ, Hiroi J, Hwang PP. Role of SLC12A10.2, a Na-Cl cotransporter-like protein, in a $\mathrm{Cl}$ uptake mechanism in zebrafish (Danio rerio). Am J Physiol Regul Integr Comp Physiol. 2009; 296: R1650-60.

40. Bakkers J, Hild M, Kramer C, Furutani-Seiki M, Hammerschmidt M. Zebrafish DeltaNp63 is a direct target of Bmp signaling and encodes a transcriptional repressor blocking neural specification in the ventral ectoderm. Dev Cell. 2002; 2. 617-27.

41. Hanssen RG, Lafeber FP, Flik G, Wendelaar Bonga SE. Ionic and total calcium levels in the blood of the European eel (Anguilla anguilla): effects of stanniectomy and hypocalcin replacement therapy. J Exp Biol. 1989; 141: $177-86$.

42. Radman DP, McCudden C, James K, Nemeth EM, Wagner GF. Evidence for calcium-sensing receptor mediated stanniocalcin secretion in fish. Mol Cell Endocrinology. 2002; 186: 111-9.

43. Fuentes J, Power DM, Canario AV. Parathyroid hormone-related protein-stanniocalcin antagonism in regulation of bicarbonate secretion and calcium precipitation in a marine fish intestine. Am J Physiol Regul Integr Comp Physiol. 2010; 299: R150-8.

44. Hwang PP, Lee TH, Lin LY. Ion regulation in fish gills: recent progress in the cellular and molecular mechanisms. Am J Physiol Regul Integr Comp Physiol. 2011; 301: R28-47.

45. van der Heijden AJ, Verbost PM, Bijvelds MJ, Atsma W, Wendelaar Bonga SE, Flik G. Effects of sea water and stanniectomy on branchial $\mathrm{Ca}^{2+}$ handling and drinking rate in eel (Anguilla anguilla L.). J Exp Biol. 1999; 202: 2505-11.

46. Horng JL, Lin LY, Hwang PP. Functional regulation of $\mathrm{H}^{+}$-ATPase-rich cells in zebrafish embryos acclimated to an acidic environment. Am J Physiol Cell Physiol. 2009; 296: C682-92.

47. Chou MY, Hsiao CD, Chen SC, Chen IW, Liu ST, Hwang PP. Effects of hypothermia on gene expression in zebrafish gills: upregulation in differentiation and function of ionocytes as compensatory responses. J Exp Biol. 2008; 211: 3077-84

48. Solomon KS, Logsdon JM, Jr., Fritz A. Expression and phylogenetic analyses of hree zebrafish FoxI class genes. Dev Dyn. 2003; 228: 301-7.

49. Janicke M, Carney TJ, Hammerschmidt M. Foxi3 transcription factors and Notch signaling control the formation of skin ionocytes from epidermal precursors of the zebrafish embryo. Dev Biol. 2007; 307: 258-71.

50. Esaki M, Hoshijima K, Nakamura N, Munakata K, Tanaka M, Ookata K, et al. Mechanism of development of ionocytes rich in vacuolar-type $\mathrm{H}^{+}$-ATPase in the skin of zebrafish larvae. Dev Biol. 2009; 329: 116-29.

51. Esaki M, Hoshijima K, Kobayashi S, Fukuda H, Kawakami K, Hirose S. Visualization in zebrafish larvae of $\mathrm{Na}^{+}$uptake in mitochondria-rich cells whose differentiation is dependent on foxi3a. Am J Physiol Regul Integr Comp Physiol. 2007; 292: R470-80. 
52. Yoshiko Y, Aubin JE, Maeda N. Stanniocalcin 1 (STC1) protein and mRNA are developmentally regulated during embryonic mouse osteogenesis: the potential of stc1 as an autocrine/paracrine factor for osteoblast development and bone formation. J Histochem Cytochem. 2002; 50: 483-92.

53. Yoshiko Y, Maeda N, Aubin JE. Stanniocalcin 1 stimulates osteoblast differentiation in rat calvaria cell cultures. Endocrinology. 2003; 144: 4134-43.

54. Wong CK, Yeung HY, Mak NK, DiMattia GE, Chan DK, Wagner GF. Effects of dibutyryl cAMP on stanniocalcin and stanniocalcin-related protein mRNA expression in neuroblastoma cells. J Endocrinol. 2002; 173: 199-209.

55. Johnston J, Ramos-Valdes Y, Stanton LA, Ladhani S, Beier F, Dimattia GE. Human stanniocalcin-1 or -2 expressed in mice reduces bone size and severely inhibits cranial intramembranous bone growth. Transgenic Res. 2010; 19: 1017-39.

56. Aberdam D, Gambaro K, Rostagno P, Aberdam E, de la Forest Divonne S, Rouleau M. Key role of p63 in BMP-4-induced epidermal commitment of embryonic stem cells. Cell Cycle. 2007; 6: 291-4. 